\title{
Peptide YY (3-36) Represents a High Percentage of Total PYY Immunoreactivity in Preterm and Full-Term Infants and Correlates Independently With Markers of Adiposity and Serum Ghrelin Concentrations
}

\author{
TANIA SIAHANIDOU, HELEN MANDYLA, HELEN MILITSI, IOANNIS PAPASSOTIRIOU, AND GEORGE CHROUSOS \\ First Department of Pediatrics [T.S., H.Mandyla, G.C.], Neonatal Unit, Athens University Medical School, 11527 Athens, Greece; \\ Department of Clinical Biochemistry [H.Militsi, I.P.], “Aghia Sophia” Children's Hospital, 11527 Athens, Greece
}

\begin{abstract}
The gut hormone peptide YY 3-36 [PYY (3-36)] has been suggested to posses anorexigenic actions in animals and human adults. However, its circulating concentrations and function have not been studied in neonates. Serum concentrations of PYY (3-36) were determined by RIA (RIA) in 62 healthy preterm infants [mean(SD) gestational age, 32.0(2.1) weeks; postnatal age, 40.9(14.8 d)] and 15 healthy fullterm infants of comparable postnatal age and gender. The correlations between PYY (3-36) levels and anthropometric characteristics, food intake, growth rates and circulating concentrations of total PYY, ghrelin, leptin, insulin and adiponectin were examined. Mean (SD) PYY (3-36) concentrations were higher in preterm [543.7(157.6) ng/L) than full term infants [350.9(114.1) ng/L; $p<$ 0.001 ) and accounted for $48 \%$ and $42 \%$ of total PYY basal plasma immunoreactivity in preterm and full term infants, respectively. In multiple regression analysis, PYY (3-36) concentrations correlated negatively with the infants' BMI and positively with serum ghrelin concentrations, but not with caloric intake, weight gain or concentrations of any other hormone studied. In conclusion, PYY (3-36) represents almost half of total PYY immunoreactivity in neonates. It's correlations with ghrelin and BMI suggest a role of this peptide in the regulation of energy homeostasis; however, its specific functions and physiologic significance in neonates remain to be elucidated. (Pediatr Res 62: 200-203, 2007)
\end{abstract}

$\mathrm{P}$ eptide YY 3-36 [PYY (3-36)] is one of the two major molecular forms of the gut peptide YY, the other isoform being PYY (1-36) (1). Both isoforms, in addition to exerting secretory and motor activities throughout the gut $(2,3)$, are involved in the central regulation of food intake and energy balance. Both peptides have an anorexigenic effect through a Y2 receptor-mediated mechanism at the level of hypothalamus, whereas PYY (1-36) also possesses orexigenic action by acting at central Y1 receptors $(3,4)$. PYY (3-36) is more potent than PYY (1-36) in several effects, such as decrease of food intake and inhibition of gastric emptying (3).

In adults, PYY (3-36) accounts for 37\% and 54\% of total PYY immunoreactivity in basal and postprandial plasma, respectively (1). However, circulating levels of PYY (3-36)

Received February 2, 2007; accepted March 21, 2007.

Correspondence: Tania Siahanidou, M.D., Ph.D., Neonatal Unit, First Department of Pediatrics, Athens University Medical School, “Aghia Sophia” Children's Hospital, 11527 Athens, Greece; e-mail: neonat5@paidon-agiasofia.gr or: siahanidou@hotmail.com This study was funded by the School of Medicine, University of Athens, Greece. have not been measured in neonates so far. The aim of the present study was to determine the circulating concentrations of PYY (3-36) in preterm and full term infants and to examine their possible associations with the infants' size, caloric intake, weight gain and the serum concentrations of total PYY or other hormones implicated in the regulation of metabolism, such as ghrelin, leptin, insulin and adiponectin $(5,6)$.

\section{METHODS}

Study population and protocol. Sixty-two preterm [mean (SD) gestational age, 32.0 (2.1) weeks; birth weight, 1542 (275) g; males, 28] and 15 healthy full term infants [gestational age, 39.0 (1.0) weeks; birth weight, 3200 (498) $\mathrm{g}$; males, 6] who served as the reference group were studied. Full term infants had similar gender distribution to that of preterm infants. Gestational age was estimated from the last menstrual period and supported by fetal ultrasound measurements and clinical examination of the neonate according to the new Ballard score (7). Preterm infants admitted to our unit were included in the study provided that 1) they had no congenital malformations or major morbidities [necrotizing enterocolitis, bronchopulmonary dysplasia, intraventricular haemorrhage greater than grade I according to the criteria of Volpe (8)], 2) their mothers had elected formula feeding, and 3) they did not have an infection during, at least, the last ten days of hospitalisation.

All infants were fed by formula that provided $670 \mathrm{Kcal} / \mathrm{L}$. The feeding protocol and the assessment of the infants' growth were described previously in a report referring to serum levels of total peptide YY and ghrelin in the same study population (9). Briefly, infants less than 32 wk of postconceptional age and/or those with immature sucking were initially given 2-hourly nasogastric tube bolus feeds. After sucking feeds had been established, the infants were offered formula every $3 \mathrm{~h}$. Finally, all infants studied were bottle-fed every 3-4 h during, at least, the last week of the study.

In preterm infants, body weight was obtained daily, using a standard electronic scale. Recumbent length and head circumference were measured weekly by the same investigator. Body mass index (BMI) of the infants at discharge was calculated $\left(\mathrm{Kg} / \mathrm{m}^{2}\right)$. Weight gain in grams per Kilogram per day was estimated since birth, as well as over the last week of hospitalisation. Full term infants were followed-up after discharge and their weight, length and head circumference were measured weakly by the same method applied to preterm infants.

Blood was obtained, before feeding, in the morning of the day of discharge in preterm infants [40.9 (14.8) days of life] and at a comparable postnatal age in full term infants [35.1 (15.3) days of life] for routine blood tests, as well as for serum PYY (3-36), total PYY, ghrelin, leptin, insulin and adiponectin level determinations. The anthropometric characteristics of the study population at testing, caloric intake, weight gain and the levels of hormones studied, but not PYY (3-36) values, were reported previously $(9,10)$ and are summarized in Table 1.

The Ethics Committee of “Aghia Sophia” Children's Hospital approved the study, and informed parental consent was also obtained for all infants studied.

Abbreviation: PYY, peptide YY 
Table 1. Characteristics of preterm and full term infants

\begin{tabular}{lcc}
\hline \multicolumn{1}{c}{ Variables } & $\begin{array}{c}\text { Preterm infants } \\
(n=62)\end{array}$ & $\begin{array}{c}\text { Full term infants } \\
(n=15)\end{array}$ \\
\hline Postnatal age, days & $40.9(14.8)$ & $35.1(15.3)$ \\
Body weight, g & $2269(162)^{*}$ & $3835(706)$ \\
Body length, cm & $46.7(0.7)^{*}$ & $54.3(3.3)$ \\
Head circumference, cm & $33.2(1.0)^{*}$ & $36.7(1.6)$ \\
BMI, Kg/m ${ }^{2}$ & $10.3(0.6)^{*}$ & $13.2(1.4)$ \\
Caloric intake over the last & $156.7(20.7)$ & $155.4(27.6)$ \\
$\quad$ & \\
week of study, cal/Kg/day & & \\
Weight gain, g/Kg/day & & $6.4(2.7)$ \\
$\quad$ Entire study period & $8.3(2.8) \dagger$ & $12.8(4.5)$ \\
$\quad$ Last week of study & $16.1(4.4)^{*}$ & $825.3(234.4)$ \\
Total PYY, ng/L & $1126.2(215.4)^{*}$ & $602.5(93.7)$ \\
Ghrelin, ng/L & $721.7(98.0)^{*}$ & $0.1-9.7($ median1.2) \\
Leptin, $\mu \mathrm{g} / \mathrm{L}$ & $0.1-15.6($ median 1.2$)$ & $0.5-10.6($ median3.1) \\
Insulin, mU/L & $0.7-22.2($ median 2.3) & $0.53 .1(16.0)$ \\
Adiponectin, mg/L & $40.8(15.3)^{*}$ & 53 \\
\hline
\end{tabular}

Data of studied groups when blood samples were drawn.

Data represent the mean $(\mathrm{SD})$, unless otherwise noted.

$*, \dagger$ Compared with full term infants; $* p \leq 0.01, \dagger p<0.05$.

Hormone assays. Serum PYY (3-36) levels were assayed by a human PYY (3-36) RIA kit (Linco Research), which utilizes an antibody specific for PYY (3-36) with no measurable cross-reactivity to PYY (1-36). The intraassay and interassay coefficients of variation (CV) were $7.0 \%$ and $6.4 \%$, respectively, and the lower limit of detection was $20 \mathrm{ng} / \mathrm{L}$. Serum concentrations of total PYY, ghrelin and adiponectin were also determined by RIA, whereas serum leptin and insulin levels were measured by ELISA and chemiluminescence immunoassay, respectively, as described previously $(9,10)$. Total PYY RIA (Linco Research) recognizes both the 1-36 and 3-36 forms of human PYY, with an interassay CV of 6.5\% and intraassay $\mathrm{CV}$ of $4.5 \%$.

Statistical analysis. Data are presented as mean (SD), unless otherwise noted. Values of PYY (3-36) were normally distributed so that no logarithmic transformation was necessary. Differences between preterm and full term infants in quantitative variables were evaluated by the Student-t or Mann Whitney-U test, as appropriate. Univariate and multiple linear regression analyses were used to examine relations among the variables of interest. Levels of statistical significance were set at $p \leq 0.05$. All statistical analyses were performed using the SPSS statistical package (SPSS, Chicago, IL).

\section{RESULTS}

Serum PYY (3-36) levels were significantly higher $(p<$ $0.001)$ in preterm [543.7 (157.6) $\mathrm{ng} / \mathrm{L}]$ than full term infants [350.9 (114.1) ng/L] and accounted for $48 \%$ and $42 \%$ of total PYY immunoreactivity in preterm and full term infants, respectively. In univariate regression analysis, serum PYY (3-36) concentrations correlated negatively with the body weight ( $\beta=-0.33, p=0.01$ in preterm infants; $\beta=-0.86$, $p<0.001$ in full term infants) or BMI of the infants at testing $(\beta=-0.38, p=0.01$ in preterm infants; $\beta=-0.77, p=$ 0.009 in full term infants) (Fig. 1), whereas they correlated positively with total PYY levels $(\beta=0.82, p<0.001$ in preterm infants; $\beta=0.72, p=0.004$ in full term infants), serum ghrelin concentrations ( $\beta=0.30, p=0.01$ in preterm infants; $\beta=0.59, p=0.02$ in full term infants) (Fig. 2) and serum insulin levels in the preterm infant group only $(\beta=$ $0.38, p=0.003)$. In preterm and full term infant groups, no significant correlation was found between serum PYY (3-36) levels and gestational age, gender, birth weight, body length or head circumference of the infants at testing, caloric intake, weight gain and levels of leptin or adiponectin.

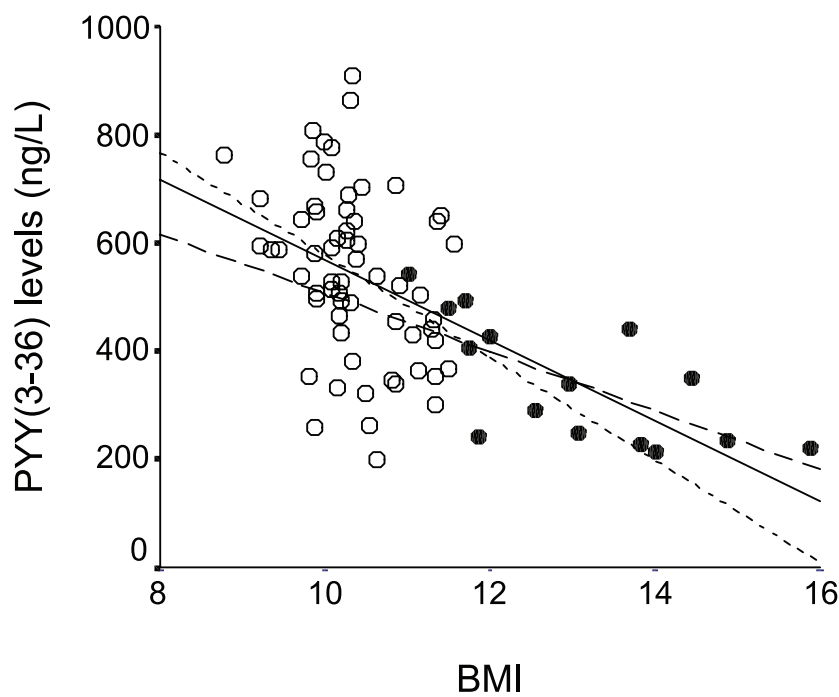

Figure 1. Correlations between serum PYY (3-36) levels and BMI. •, full term infants; $\circ$, preterm infants. The lines represent the regression slope separately for the groups of full term $(-\ldots \ldots ; \beta=-0.77, p=0.009)$ and preterm infants $(--\beta=-0.38, p=0.01)$ and for the entire study population $(-; \beta=-0.62, p<0.001)$.

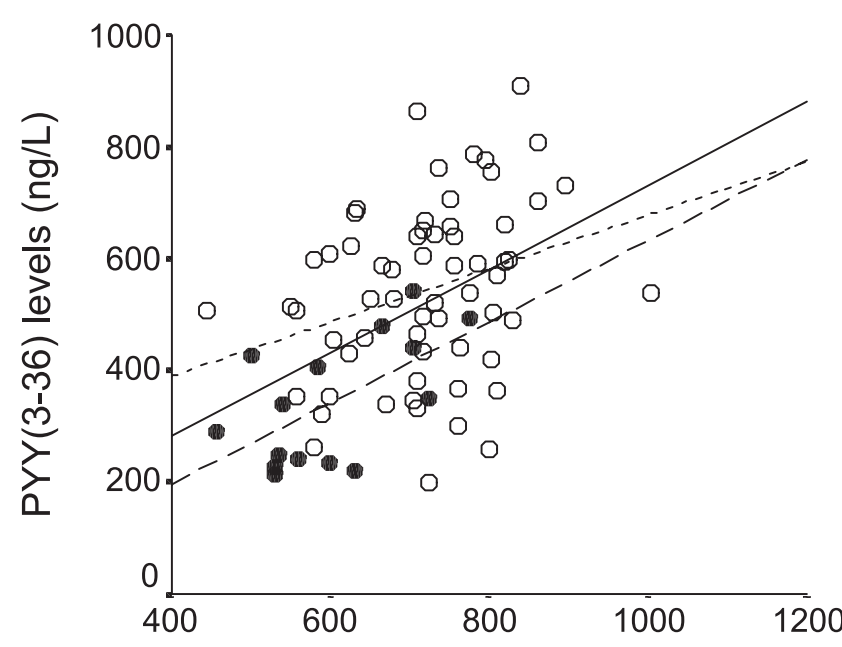

\section{Ghrelin levels (ng/L)}

Figure 2. Correlations between serum PYY (3-36) and ghrelin levels. $\bullet$, full term infants; $\odot$, preterm infants. The lines represent the regression slope separately for the groups of full term $(-\ldots-; \beta=0.59, p=0.02)$ and preterm infants $(---; \beta=0.30, p=0.01)$ and for the entire study population $(-; \beta=0.46, p<0.001)$.

After adjustment for body weight or BMI, the influence of prematurity on serum PYY (3-36) levels did not remain significant. On multiple regression analysis modelling with gestational age, gender, BMI, caloric intake, weight gain, ghrelin and insulin levels entered into the model, the only significant and independent predictors of PYY (3-36) concentrations were BMI $(\beta=-0.66, p=0.001)$ and ghrelin levels $(\beta=0.30, p=0.02)\left(\mathrm{r}^{2}\right.$ of the model $\left.=0.52, p<0.001\right)$. If BMI was substituted by body weight in the regression model, the independent predictors of PYY (3-36) concentrations were body weight $(\beta=-0.51, p=0.005)$ and ghrelin levels $(\beta=$ $0.27, p=0.02)\left(\mathrm{r}^{2}\right.$ of the model $\left.=0.45, p<0.001\right)$. 


\section{DISCUSSION}

According to the results of this study, serum PYY (3-36) concentrations were higher in preterm than full term infants of comparable postnatal age and much higher than levels estimated from previous reports on total PYY levels in older children (11) and adults (2). However, after adjustment for body weight or BMI of the infants at testing, the influence of prematurity on PYY (3-36) concentrations did not remain significant. Interestingly, BMI, or body weight, were identified as independent negative predictors of PYY (3-36) levels. BMI constitutes a marker of adiposity and body weight, in neonates, also correlates positively with body fat mass as assessed by dual-energy x-ray absorptiometry (12). Thus, the increased PYY (3-36) levels in our preterm infants are, at least partly, possibly due to their decreased adiposity. A negative association between PYY levels and markers of adiposity has also been reported in adolescents (13) and adults (14), but it is not clear from these studies whether PYY levels have an effect on adiposity or they are influenced by fat mass. Although a correlation between PYY levels and markers of adiposity was not a consistent finding in other studies $(15,16)$, it cannot be excluded that factors related to fat mass may affect the synthesis/release of PYY; however, the precise factors and underlying mechanisms remain to be determined.

To our knowledge, this is the first study in which the circulating levels of PYY (3-36) were directly measured in preterm and full term infants. We found that PYY (3-36) accounted for a high percentage (almost 50\%) of total PYY immunoreactivity in our study population, similarly to previous reports in adults (1), and in accordance with the demonstration of both isoforms of PYY, in equal amounts, in fetal intestinal tissues (17). However, it contradicts the results of the study of Adrian et al. showing that, on gel permeation chromatography, the majority of circulating PYY-like immunoreactivity, in the neonate, eluted in an identical position to the pure 36 amino acid PYY standard; thus represented the PYY (1-36) (18). As that method was not specific in the detection of the PYY (3-36) isoform, the discrepancy between the results of that study and ours is probably due to the different methodology applied.

Serum ghrelin concentrations were also identified as independent predictors of serum PYY (3-36) levels. Although interventional studies assessing a possible influence of ghrelin on the synthesis/release of PYY (3-36) have not been conducted so far, an i.v. infusion of PYY (3-36) in humans suppressed plasma ghrelin levels (14). Both ghrelin and PYY levels were low in states associated with obesity (14), while they were elevated and correlated positively with each other in negative body weight balance, such as in anorexia nervosa (13). Thus, in our study population, PYY (3-36) levels may increase to counteract an elevation in ghrelin levels. This is consistent to the opposite effects of ghrelin and PYY (3-36) on food intake and energy balance (5). Observations in animals suggest that PYY may contribute to signaling a positive status of energy intake by inhibiting the hypothalamic arcuate neurons, which are activated under a negative status of energy intake by signals such as ghrelin (19). However, Adams et al. provided evidence of dissociation between PYY activity and the regulation of ghrelin levels; PYY (3-36) administration in animals, lowered food intake without altering plasma ghrelin concentrations and regardless of prevailing endogenous plasma ghrelin levels (20). In addition, no difference in postabsorptive plasma acyl-ghrelin (the active form of ghrelin) was observed between PYY knockout and wild animals (20).

PYY (3-36) levels correlated positively with insulin levels in preterm infants only. Although the absence of such a correlation in full term infants may be due to their limited number, it is in accordance with previous studies in older children and adults $(16,21)$. We reported previously that insulin levels tended to be higher in preterm than in full term infants after adjustment for body weight and a negative correlation between insulin levels and the body weight of preterm infants was observed (10). Under hyperinsulinemic conditions, PYY (3-36) reinforces insulin action on glucose disposal in animals, thus exerting an insulin sensitizing effect (22); whether PYY (3-36) increases in our preterm infants to exert such an action is not known. In addition, body weight might be behind the correlation found between insulin and PYY (3-36) levels in preterm infants. In fact, after controlling for body weight or BMI at discharge, the influence of insulin on serum PYY (3-36) levels did not remain significant.

The precise role and specific functions of PYY (3-36) in preterm and full term infants are not known. Although we did not observe any correlation between PYY (3-36) levels and caloric intake or weight gain in our study population, this may be due to the especially complex processes involved in the regulation of food intake and body weight balance (5). Whether the elevated levels of PYY (3-36) in neonates, especially in the preterms, are related to the involvement of this peptide in the regulation of energy homeostasis and/or to effects on the gut $(2,3)$, including absorptive, trophic and proliferative actions (23-25), or to more systemic phenomena, such as enhancement of insulin sensitivity (22) and inhibition of lipolysis (26), remains to be determined.

\section{REFERENCES}

1. Grandt D, Schimiczek M, Beglinger C, Layer P, Goebell H, Eysselein VE, Reeve JR 1994 Two molecular forms of peptide YY (PYY) are abundant in human blood: characterization of a radioimmunoassay recognizing PYY 1-36 and PYY 3-36. Regul Pept 51:151-159

2. Onaga T, Zabielski R, Kato S 2002 Multiple regulation of peptide YY secretion in the digestive tract. Peptides 23:279-290

3. Chelikani PK, Haver AC, Reidelberger RD 2005 Intravenous infusion of PYY(3-36) potently inhibits food intake in rats. Endocrinology 146:879-888

4. Batterham RL, Cowley MA, Small CJ, Herzog H, Cohen MA, Dakin CL, Wren AM, Brynes AE, Low MJ, Ghatel MA, Cone RD, Bloom SR 2002 Gut hormone PYY (3-36) physiologically inhibits food intake. Nature 418:650-654

5. Schwartz MW, Morton GJ 2002 Keeping hunger at bay. Nature 418:595-597

6. Meier U, Gressner AM 2004 Endocrine regulation of energy metabolism: Review of pathobiochemical and clinical chemical aspects of leptin, ghrelin, adiponectin and resistin. Clin Chem 50:1511-1525

7. Ballard JL, Khoury JC, Wedig K, Wang L, Eilers-Walsman BL, Lipp R 1991 New Ballard Score, expanded to include extremely premature infants. J Pediatr 119:417-423

8. Volpe JJ 2001 Intracranial hemorrhage: germinal matrix-intraventricular hemorrhage of the premature infant. In: Volpe JJ (ed) Neurology of the newborn. WB Saunders, Philadelphia, pp 428-493

9. Siahanidou T, Mandyla H, Vounatsou M, Anagnostakis D, Papassotiriou I, Chrousos GP 2005 Circulating levels of PYY are higher in preterm than term infants and correlate negatively with body weight and positively with serum ghrelin levels. Clin Chem 51:2131-2137

10. Siahanidou T, Mandyla H, Papassotiriou GP, Papassotiriou I, Chrousos G 2006 Circulating levels of adiponectin in preterm infants. Arch Dis Child Fetal Neonatal Ed [Epub ahead of print] 
11. Roth CL, Enriori PJ, Woelfle J, Cowley MA, Reinehr T 2005 Peptide YY is a regulator of energy homeostasis in obese children before and after weight loss. J Clin Endocrinol Metab 90:6386-6391

12. Rigo J, Nyamugabo K, Picaud JC, Gererd P, Pieltain C, De Curtis M 1998 Reference values of body composition obtained obtained by dual energy $\mathrm{x}$-ray absorsptiometry in preterm and term neonates. J Pediatr Gastroenterol Nutr 27:184-190

13. Misra M, Miller KK, Tsai P, Gallagher K, Lin A, Lee N, Herzog DB, Klibanski A 2006 Elevated Peptide YY levels in adolescent girls with anorexia nervosa. J Clin Endocrinol Metab 91:1027-1033

14. Batterham RL, Cohen MA, Ellis SM, Le Roux CW, Withers DJ, Frost GS, Ghatei MA, Bloom SR 2003 Inhibition of food intake in obese subjects by peptide $\mathrm{YY}_{3-36}$. N Engl J Med 349:941-948

15. Stock S, Leichner P, Wong AC, Ghatei MA, Kieffer TJ, Bloom SR, Chanoine JP 2005 Ghrelin, peptide YY, glucose-dependent insulinotropic polypeptide, and hunger responses to a mixed meal in anorexic, obese, and control female adolescents. J Clin Endocrinol Metab 90:2161-2168

16. Bacha F, Arslanian SA 2006 Ghrelin and PYY in youth: are there race-related differences? J Clin Endocrinol Metab 91:3117-3122

17. Xiao Q, Han X, Arany E, Hill D, Challis JR, McDonald TJ 1998 Human placenta and fetal membranes contain peptide $\mathrm{YY}_{1-36}$ and peptide $\mathrm{YY}_{3-36}$. J Endocrinol $156: 485-492$

18. Adrian TE, Smith HA, Calvert SA, Aynsley-Green A, Bloom SR 1986 Elevated plasma peptide YY in human neonates and infants. Pediatr Res 20:1225-1227
19. Riediger T, Bothe C, Becskei C, Lutz TA 2004 Peptide YY directly inhibits ghrelin-activated neurons of the arcuate nucleus and reverses fasting-induced c-Fos expression. Neuroendocrinology 79:317-326

20. Adams SH, Won WB, Schonhoff SE, Leiter AB, Paterniti JR 2004 Effects of peptide $\mathrm{YY}(3-36)$ on short-term food intake in mice are not affected by prevailing plasma ghrelin levels. Endocrinology 145:4967-4975

21. Guo Y, Ma L, Enriori PJ, Koska J, Franks PW, Brookshire T, Cowley MA, Salbe AD, DelParigi A, Tataranni PA 2006 Physiological evidence for the involvement of peptide YY in the regulation of energy homeostasis in humans. Obesity (Silver Spring) 14:1562-1570

22. van den Hoek AM, Heijboer AC, Corssmit EP, Voshol PJ, Romijn JA, Havekes LM, Pijl H 2004 PYY $_{3-36}$ reinforces insulin action on glucose disposal in mice fed a high-fat diet. Diabetes 53:1949-1952

23. Liu CD, Aloia T, Adrian TE, Newton TR, Bilchik AJ, Zinner MJ, Ashley SW, McFadden DW 1996 Peptide YY: a potential proabsorptive hormone for the treatment of malabsorptive disorders. Am Surg 62:232-236

24. Mannon PJ 2002 Peptide YY as a growth factor for intestinal epithelium. Peptides 23:383-388

25. Gomez G, Zhang T, Rajaraman S, Thakore KN, Yanaihara N, Townsend CM Thompson JC, Greeley GH 1995 Intestinal peptide YY: ontogeny of gene expression in rat bowel and trophic actions on rat and mouse bowel. Am J Physiol 268:G71-G81

26. Castan I, Valet P, Larrouy D, Voisin T, Remaury A, Daviaud D, Laburthe M, Lafontan M 1993 Distribution of PYY receptors in human fat cells: an antilipolytic system alongside the alpha 2-adrenergic system. Am J Physiol 265:E74-E80 